\title{
Adaptability and stability of genotypes of sweet sorghum by GGEBiplot and Toler methods
}

\author{
U.J. de Figueiredo ${ }^{1}$, J.A.R. Nunes ${ }^{1}$, R.A. da C. Parrella ${ }^{2}$, E.D. Souza ${ }^{3}$, \\ A.R. da Silva ${ }^{2}$, B.M. Emygdio ${ }^{4}$, J.R.A. Machado ${ }^{2}$ and F.D. Tardin ${ }^{2}$ \\ ${ }^{1}$ Departamento de Biologia, Universidade Federal de Lavras, Lavras, MG, Brasil \\ ${ }^{2}$ Embrapa Milho e Sorgo, Sete Lagoas, MG, Brasil \\ ${ }^{3}$ Embrapa Roraima, Boa Vista, RR, Brasil \\ ${ }^{4}$ Embrapa Clima Temperado, Pelotas, RS, Brasil \\ Corresponding author: U.J. de Figueiredo \\ E-mail: ujfigueiredo@yahoo.com.br \\ Genet. Mol. Res. 14 (3): 11211-11221 (2015) \\ Received January 23, 2015 \\ Accepted May 15, 2015 \\ Published September 22, 2015 \\ DOI http://dx.doi.org/10.4238/2015.September.22.15
}

\begin{abstract}
Sweet sorghum has considerable potential for ethanol and energy production. The crop is adaptable and can be grown under a wide range of cultivation conditions in marginal areas; however, studies of phenotypic stability are lacking under tropical conditions. Various methods can be used to assess the stability of the crop. Some of these methods generate the same basic information, whereas others provide additional information on genotype $\mathrm{x}$ environment $(\mathrm{G} x \mathrm{E})$ interactions and/or a description of the genotypes and environments. In this study, we evaluated the complementarity of two methods, GGEBiplot and Toler, with the aim of achieving more detailed information on $\mathrm{G} x$ $E$ interactions and their implications for selection of sweet sorghum genotypes. We used data from 25 sorghum genotypes grown in different environments and evaluated the following traits: flowering (FLOW), green mass yield (GMY), total soluble solids (TSS), and tons of Brix per hectare (TBH). Significant G x E interactions were found for all
\end{abstract}


traits. The most stable genotypes identified with the GGEBiplot method were CMSXS643 for FLOW, CMSXS644 and CMSXS647 for GMY, CMSXS646 and CMSXS637 for TSS, and BRS511 and CMSXSS647 for TBH. Especially for TBH, the genotype BRS511 was classified as doubly desirable by the Toler method; however, unlike the result of the GGEBiplot method, the genotype CMSXS647 was also found to be doubly undesirable. The two analytical methods were complementary and enabled a more reliable identification of adapted and stable genotypes.

Key words: Complementarity method; Ethanol; Multi-environment trial; Genotype x environment interaction; Sorghum bicolor

\section{INTRODUCTION}

Sweet sorghum [Sorghum bicolor (L.) Moench] is a bioenergy crop with considerable potential to contribute significantly to ethanol production in Brazil. The harvest time of the crop is complementary to that of sugar cane and thus not only contributes to an increased ethanol production but also reduces the period of inactivity of ethanol processing plants. Sweet sorghum is highly tolerant to abiotic stresses and can be used for renewal of sugarcane fields due to its short life cycle of 4 months (Souza et al., 2013).

Improvement in sweet sorghum breeding requires evaluation of the performances of candidate cultivars in trials of value for cultivation and use (VCU). Such VCU trials are required by the Ministry of Agriculture, Livestock and Supply (MAPA), which aims to validate potential genotypes under different crop conditions and to promote trustworthy and reliable comparisons with cultivars on the market. After these assessments, breeders can use the appropriate biometric procedures to identify the genotypes best suited and most stable in a particular region and to recommend these to farmers.

Nevertheless, there have been few studies on the adaptability and stability of sweet sorghum with respect to the impact of genotype $\times$ environment $(\mathrm{G} \times \mathrm{E})$ interactions (Rao et al., 2011; Souza et al., 2013). Various methods are available for investigating G x E interactions (Ferreira et al., 2006). For example, multivariate methods can be used to analyze adaptability and phenotypic stability: the AMMI method (Additive Main Effects and Multiplicative Interaction) combines additive terms for main effects (genotype and environment) and multiplicative terms for G x E interaction effects into a single model (Gauch, 2013); the GGEBiplot method combines the main effects of genotype with the multiplicative effects of the $\mathrm{G} \times \mathrm{E}$ interaction (Yan, 2001, 2013). Although these methods are very informative, they are unable to describe the response pattern of genotypes to variation in environmental quality (Ferreira et al., 2006; Yan and Tinker, 2006). The analytical method proposed by Toler (1990) can provide this information.

Here, the complementarity of the GGEBiplot and Toler analytical methods was examined in order to better define $\mathrm{G} x \mathrm{E}$ interactions and to determine whether these methods can be jointly applied to the analysis of adaptability and phenotypic stability of sweet sorghum genotypes in multi-environment trials.

\section{MATERIAL AND METHODS}

This study includes data from nine trials to determine the VCU of sweet sorghum 
varieties. These trials were conducted by the Brazilian Corporation for Agricultural Research (Embrapa) Maize and Sorghum in the 2011/2012 growing year (Table 1).

The trials evaluated 25 genotypes, including 18 varieties developed by the breeding program of Embrapa Maize and Sorghum (BR501, BR505, BRS506, BRS508, BRS509, BRS511, CMSXS629, CMSXS630, CMSXS633, CMSXS635, CMSXS636, CMSXS637, CMSXS639, CMSXS643, CMSXS644, CMSXS646, CMSXS647, and CMSXS648) and 7 commercial hybrids released by Embrapa Maize and Sorghum (BRS601), by Advanta (Sugargraze, V82391, V82392, and V82393) and by Monsanto (XBSW80007 and XBSW80140). All the varieties from the breeding program of Embrapa Maize and Sorghum are lines, and the hybrids are all simple hybrids. The experimental design was a triple-square lattice. The experimental plot consisted of four rows of $5 \mathrm{~m}$. The spacing between rows was $0.7 \mathrm{~m}$ and the approximate population density was 140,000 plants per hectare. Fertilizer was added at a rate of $400 \mathrm{~kg} / \mathrm{ha}$ NPK $08-28-16$ at planting and $200 \mathrm{~kg} / \mathrm{ha}$ urea as a top dressing.

In the trials, the flowering period (FLOW) of each genotype was estimated as the time when approximately $50 \%$ of the plants in the plot were in flower. Before harvesting, the total number of plants per plot was counted. The experimental plots were cut at physiological maturity of the grain. In each plot, we measured the green mass yield $(\mathrm{kg})$, which was converted into green mass yield per hectare (GMY). Ten stalks per plot were ground and pressed in a hydraulic press (Sete Lagoas and Pelotas) or a mill for juice extraction and determination of the extraction yield (\%EXT). A juice sample was used to determine the total soluble solid content (TSS) using an automatic digital refractometer ( ${ }^{\circ}$ Brix). After that, we estimated the tons of Brix per hectare (TBH) as the product of GMY x \%EXT x TSS.

The FLOW, GMY, TSS, and TBH trait data were subjected to analysis with recovery of interblock information by environment, in which seven environments were used for FLOW (except Mata Roma and Passo Fundo) and eight for GMY (except Pelotas), TSS and TBH (except Goiânia). Homogeneity of residual variances was tested by the Bartlett test at $5 \%$ probability. In the case of heteroscedasticity, we standardized the phenotypic data by multiplying the data of each trait in each environment using the following factor $\sqrt{r_{a}^{2}} / \sqrt{r_{\varepsilon^{2}}^{2}}$ (Resende et al., 2008), where $r^{2}{ }_{c j}$ is the coefficient of genotypic determination for the trait $c$ in the environment $j$ and $\overline{r_{c}^{2}}$ is the average coefficient of genotypic determination of environments to the trait $c$.

After, we performed the multi-environment analysis according to the following model:

$$
y_{i j k l}=\mu+e_{j}+r_{k(j)}+b_{l(j k)}+g_{i}+g e_{i j}+\varepsilon_{i j k l} \quad \text { (Equation 1) }
$$

where $Y_{i j k l}:$ value observed of the plot in the block $l$ within the repetition $k$ in the environment $j$, which received the genotype $i$; $e_{j}$ : effect of the environment $j ; r_{k(j)}$ : effect of the repetition $k$ in the environment $j ; b_{l(j k)}$ : effect of the block $l$ within the repetition $k$ in the environment $j, b_{l(j k)}$ $\sim \mathrm{N}\left(0, \sigma_{\mathrm{b}}^{2}\right) ; g_{i}$ : effect of the genotype $i ; g e_{i j}$ : effect of the genotype by environment interaction associated with genotype $i$ and environment $j ; \varepsilon_{i j k l}$ : effect of the within-environment error associated with observation $y_{i j k l}$, where $i j k l \sim \mathrm{N}\left(0, \sigma_{\mathrm{b}}{ }^{2}\right)$.

The analyses (by environment and joint) were using Henderson's mixed model approach. The restricted maximum likelihood method was used to estimate the variance associated with random effects. The experimental precision was measured by selective accuracy (Resende and Duarte, 2007) expressed by: $r_{\hat{g} g}=[1-(1 / F)]^{1 / 2}$, where $F$ is the Snedecor's F value associated with genotype effect. Moreover, we estimated the least square means of the geno- 
types in each environment to perform the analyses of stability and adaptability. The adjusted means were grouped by Scott-Knott test (Scott and Knott, 1974).

To describe the response pattern of each genotype in the evaluated environments, we proceeded to adjust according to the following non-linear models [single-straight line or nonsegmented (Equation 2) and extended or bi-segmented model (Equation 3)] proposed by Toler and Burrows (1998):

$$
\begin{gathered}
Y_{i j}=\alpha_{i}+\beta_{i} \mu_{j}+\delta_{i j}+\varepsilon_{i j} \\
Y_{i j}=\alpha_{i}+\left[Z_{j} \beta_{1 i}+\left(1-Z_{j}\right) \beta_{2 i}\right] \mu_{j}+\delta_{i j}+\varepsilon_{i j} \quad \text { (Equation 2) }
\end{gathered}
$$

where $Y_{i j}$ : adjusted mean of the genotype $i(i=1,2, \ldots, p)$ in the environment $j ; \alpha_{i}$ : response intercept value at $\mu_{j}=0$ associated with genotype $i ; \beta_{1 i}$ and $\beta_{2 i}$ : regression coefficients related to response sensitivity of the genotype $i$ in environments of lower and higher quality, respectively; $\mu_{j}$ : denotes the effect of the environment $j ; \beta_{i}$ : regression coefficient quantifying the response sensitivity of the genotype $i$ in different environments; $\delta_{i j}$ : deviation of the regression of the genotype $i$ in the environment $j ; \varepsilon_{i j}$ : average experimental error; $Z_{j}=1$, if $\mu_{j} \leq 0$ and, $Z_{j}$ $=0$, if $\mu_{j} \geq 0$.

In the model, the imposed restrictions $\sum_{i}^{p} \hat{\beta}_{1 i}=\sum_{i}^{p} \hat{\beta}_{2 i}=p$ and $\sum_{i}^{q} \hat{\mu}_{j}=0$ are required so that the average performance of genotypes $\left(\hat{\alpha}_{i}\right)$ takes place with $\hat{\mu}=0$ in the scale of $\hat{\mu}_{j}$ environmental effects and that their response to the average sensitivity is equal to unit (Rosse and Vencovsky, 2000).

The response patterns of the genotypes were then categorized into five groups according to Toler (1990): Group A - Criterion: reject $\mathrm{H}_{0}: \beta_{1 i}=\beta_{2 i}$, with $\beta_{1 i}<1<\beta_{2 i}$; Group B - Criterion: does not reject $\mathrm{H}_{0}: \beta_{1 i}=\beta_{2 i}$, reject $\mathrm{H}_{0}: \beta_{1 i}=1$, but common $\beta_{i}$ is higher than 1 ; Group $\mathrm{C}$ - Criterion: does not reject $\mathrm{H}_{0}: \beta_{1 i}=\beta_{2 i}$, accept $\mathrm{H}_{0}: \beta_{1 i}=1$; Group D - Criterion: does not reject $\mathrm{H}_{0}: \beta_{1 i}=\beta_{2 i}$, reject $\mathrm{H}_{0}: \beta_{1 i}=1$, but common $\beta_{i}$ is lower than 1 ; Group $\mathrm{E}$ - Criterion: reject $\mathrm{H}_{0}$ : $\beta_{1 i}=\beta_{2 i}$, with $\beta_{1 i}>1>\beta_{2 i}$.

For the Toler method, we used the Estabilidade3.0 software (Build 13) (Ferreira and Zambalde, 1997). We also estimated Spearman's rank correlation between the observed and fitted means according to the Toler non-linear models, to check the predictability of genotype behavior.

For the GGEBiplot analysis, we used the singular value decomposition of the matrix $\mathrm{G}+\mathrm{GE}$ according to the model in Equation 4 (Yan, 2001):

$$
G+G E=\left[\left(g_{i}+g e_{i j}\right)\right]=\lambda_{1} \gamma_{i 1} \delta_{j 1}+\lambda_{2} \gamma_{i 2} \delta_{j 2}+\rho_{i j}
$$

where $G+G E$ : matrix of the effects of genotypes added to the effects of genotype x environment interactions; $\lambda_{1}$ and $\lambda_{2}$ : singular values of the first and second principal components; $Y_{i 1}$ and $Y_{i 2}$ : eigenvectors of the first and second principal components associated with the effect of the genotype $i$; $\delta_{j 1}$ and $\delta_{j 2}$ : eigenvectors of the first and second principal components associated 
with the effect of the environment $j ; \rho_{i j}$ : residual of the model associated with the genotype $i$ in environment $j$.

The scores of genotypes and environments were calculated from the estimates of singular values and eigenvectors associated with the principal components (Yan, 2001). We generated biplot graphs to better understand the interrelationship among genotypes and/or environments, as proposed by Yan and Tinker (2006). This analysis was performed using the GGEBiplot software (Yan, 2001).

\section{RESULTS AND DISCUSSION}

The results of the joint analysis demonstrated selective accuracy above $95 \%$ for all traits. According to Resende and Duarte (2007), these magnitudes represent a very high experimental precision, i.e., they indicate good reliability of the experimental data for selective purposes.

A significant environmental effect $(\mathrm{P}<0.01)$ was found for all traits, indicating differences among environments; these differences may be due to variations in macro-environmental aspects, such as soil type, climate, altitude, geography, and/or differences related to the crop cycle in the studied environments (Table 1). Such information is of value for the breeder given that the aim is selection of high-performance genotypes under different conditions of cultivation.

Table 1. Geographical description of the nine trial environments, date of planting, of harvesting, and crop cycle of value for cultivation and use trials in 2011/2012.

\begin{tabular}{|c|c|c|c|c|c|c|c|}
\hline Locations & Abbreviation & Latitude & Longitude & Altitude & Planting & Harvesting & Cycle \\
\hline Boa Vista - RR & $\mathrm{BV}$ & $02^{\circ} 49^{\prime} \mathrm{S}$ & $60^{\circ} 40^{\prime} \mathrm{W}$ & $85 \mathrm{~m}$ & $07 / 17 / 2012$ & $11 / 01 / 2012$ & 107 \\
\hline Goiânia - GO & GO & $16^{\circ} 40^{\prime} \mathrm{S}$ & $49^{\circ} 15^{\prime} \mathrm{W}$ & $823 \mathrm{~m}$ & $03 / 13 / 2012$ & $07 / 10 / 2012$ & 119 \\
\hline Janaúba - MG & $\mathrm{JN}$ & $15^{\circ} 48^{\prime} \mathrm{S}$ & $43^{\circ} 18^{\prime} \mathrm{W}$ & $533 \mathrm{~m}$ & $12 / 09 / 2011$ & $04 / 10 / 2012$ & 123 \\
\hline Mata Roma - MA & MR & $03^{\circ} 37^{\prime} \mathrm{S}$ & $43^{\circ} 06^{\prime} \mathrm{W}$ & $80 \mathrm{~m}$ & $02 / 10 / 2012$ & $05 / 19 / 2012$ & 99 \\
\hline Passo Fundo - RS & $\mathrm{PF}$ & $28^{\circ} 15^{\prime} \mathrm{S}$ & $52^{\circ} 24^{\prime} \mathrm{W}$ & $687 \mathrm{~m}$ & $01 / 13 / 2012$ & $05 / 15 / 2012$ & 123 \\
\hline Pelotas - RS & PE & $31^{\circ} 46^{\prime} \mathrm{S}$ & $52^{\circ} 20^{\prime} \mathrm{W}$ & $7 \mathrm{~m}$ & $12 / 13 / 2011$ & $04 / 28 / 2012$ & 137 \\
\hline Sete Lagoas - MG & SL & $19^{\circ} 27^{\prime} \mathrm{S}$ & $44^{\circ} 14^{\prime} \mathrm{W}$ & $767 \mathrm{~m}$ & $11 / 10 / 2011$ & $03 / 02 / 2012$ & 113 \\
\hline Sinop - MT & SI & $11^{\circ} 50^{\prime} \mathrm{S}$ & $55^{\circ} 38^{\prime} \mathrm{W}$ & $384 \mathrm{~m}$ & $11 / 29 / 2011$ & $03 / 22 / 2012$ & 114 \\
\hline Capão do Leão - RS & $\mathrm{TB}$ & $31^{\circ} 45^{\prime} \mathrm{S}$ & $52^{\circ} 29^{\prime} \mathrm{W}$ & $21 \mathrm{~m}$ & $12 / 04 / 2011$ & $04 / 30 / 2012$ & 148 \\
\hline
\end{tabular}

The effect of genotype was highly significant $(\mathrm{P}<0.01)$ for all traits, demonstrating that the observed differences in performances had genetic causes and, thereby, offer the possibility of selection and genetic gains.

In light of the significant genetic and environmental variations, $\mathrm{G} \times \mathrm{E}$ interactions have increased importance. Significant G x E effects $(P<0.01)$ were found for all traits, indicating the need to perform additional biometrical procedures to evaluate their influence on adaptability and stability of sweet sorghum genotypes. In the presence of a significant $\mathrm{G} x \mathrm{E}$ interaction, there is a differential response of genotypes to the environments evaluated, and there may even be genotypes that display specific adaptability. Several analytical methods have been published that can be used to study the adaptability and stability of genotypes in VCU trials with the goal of assisting breeders by releasing the best genotypes as cultivars.

On this basis, Ferreira et al. (2006) reported that some methods used in stability studies can be complementary. For example, although the AMMI method does not allow analysis of G $\mathrm{x} E$ interactions, it could be supplemented by the use of a non-linear regression method, such 
as that of Toler (1990).

The multivariate GGEBiplot method (Yan, 2001) has been widely used in studies of adaptability and phenotypic stability (Oliveira et al., 2010; Rao et al., 2011; Mattos et al., 2013) due to its versatility and informative graphical interfaces, which are easy to view and informative to breeders (Yan and Kang, 2003). Nevertheless, the GGEBiplot method does not clearly describe genotypic responses in different environments, but can be supplemented by the Toler (1990) method.

In the present study, the GGEBiplot analysis resulted in a cumulative explanation along the first two principal components of $90.2 \%$ (FLOW), $81.5 \%$ (GMY), $84.9 \%$ (TSS), and $82.9 \%$ (TBH). These results indicate that the performance of the different genotypes in the studied environments, as represented by graphic patterns, had high reliability given the contribution of the total variation of genotype performance added to the $\mathrm{G} x \mathrm{E}$ interactions $(\mathrm{G}+\mathrm{GxE})$.

The direction and magnitude of the correlation between the environments are illustrated in Figure 1 by the cosine of the angles between the vectors of the environments from the origin.
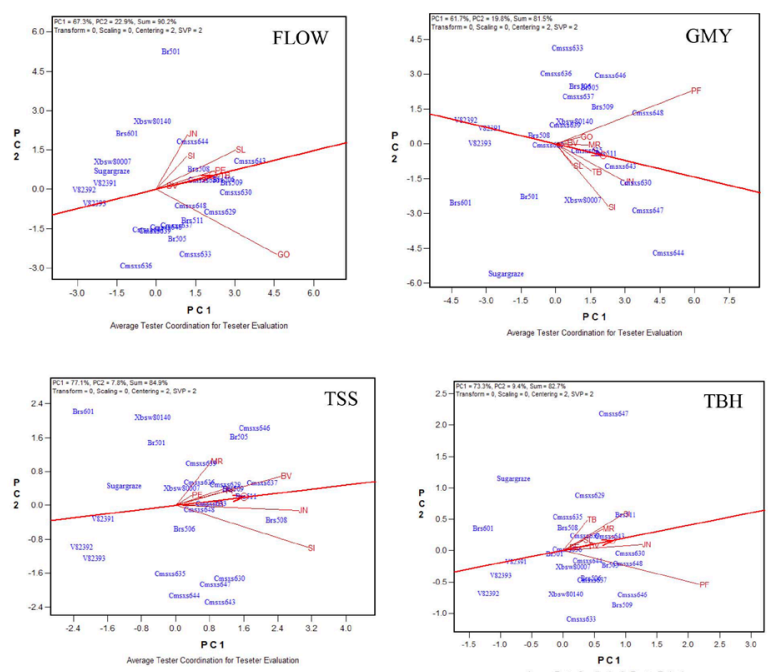

Figure 1. GGEBiplot graph showing the discrimination and representativeness of the test environments in relation to flowering (FLOW), green mass yield (GMY), total soluble solids (TSS), and tons of Brix per hectare (TBH). Names in blue represent genotypes, the abbreviations in red are trial plot locations (see Table 1).

For FLOW, Goiânia showed no correlation with Janaúba but had a positive correlation with other environments. In general, the traits GMY, TSS, and TBH had positive environmental correlations. Environments with highly positive correlations may indicate that the genotypes are similarly ranked, raising the possibility of using only one or a few environments that enable high discrimination for this purpose; this would be especially true if the associations have repeatability over many years, and therefore could be used with minimal loss of information. In Figure 1, the continuous line is the average environment axis and environments with smaller angles to this line are the most representative. Thus, Boa Vista is the most representative for TBH, Terras Baixas for TSS, Mata Roma for GMY, and Pelotas, Boa Vista, and Terras Baixas for FLOW. These environments are representative, but not distinctive, since they have 
a short axis relative to the origin; thus, they are not good testing environments to select widely adapted genotypes (Yan et al., 2011).

With regard to identification of mega-environments on the basis of winning genotypes, the GMY and TSS traits formed two groups of testing environments. For GMY, a group was formed by Goiânia and Passo Fundo, and for TSS, the group was formed by Pelotas and Mata Roma (Figure 2). For FLOW, three groups of testing environment were determined: one involved only Goiânia; the second group included Janaúba and Sinop; and the third included the other environments. TBH likewise formed three groups: one was formed by only Passo Fundo; the second by Janaúba and Boa Vista; and the third group contained the other environments.
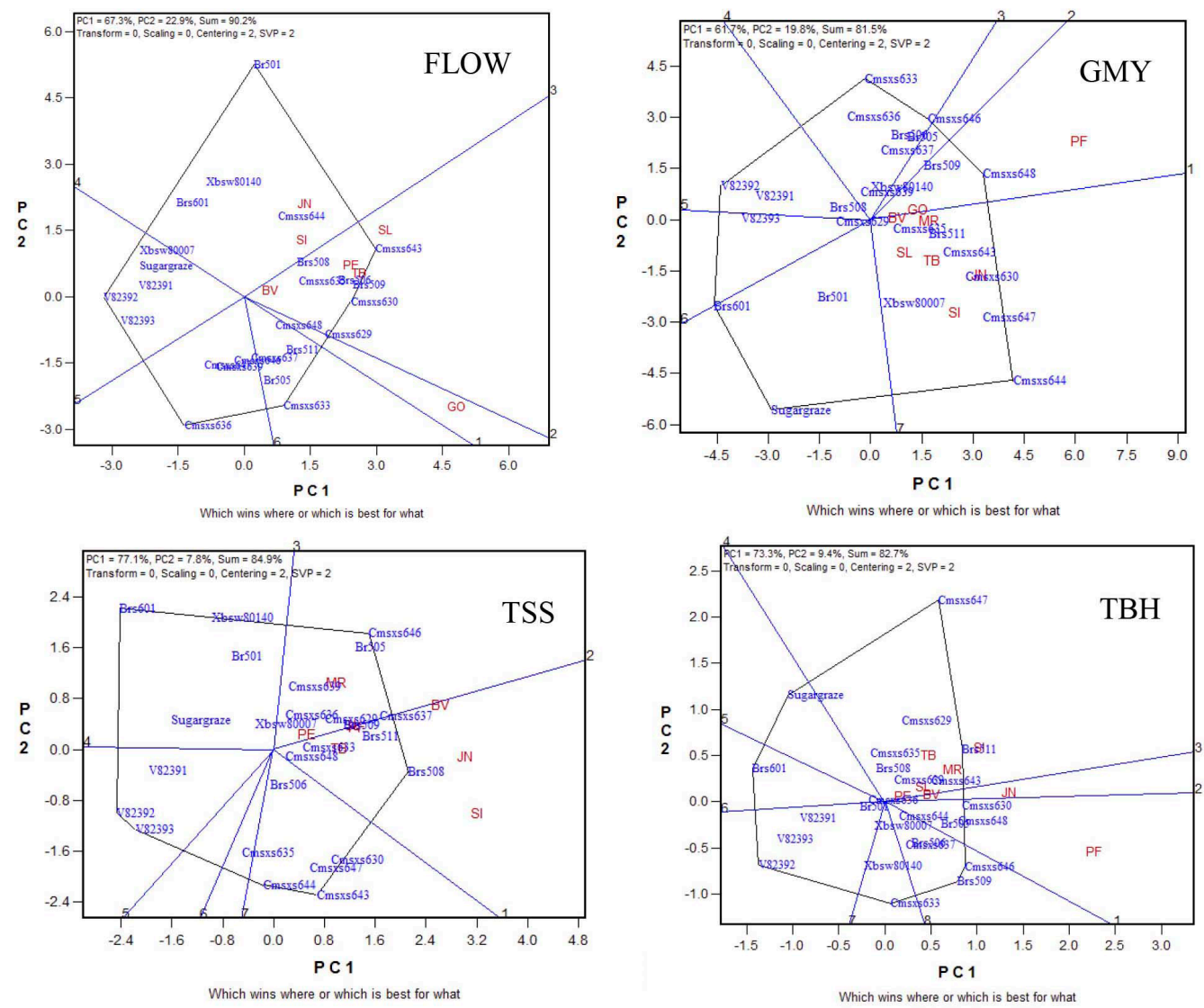

Figure 2. Groups of mega-environments for flowering (FLOW), green mass yield (GMY), total soluble solids (TSS), and tons of Brix per hectare (TBH).

The criteria for the formation of mega-environments are that there are significant differences between the genotypes in different environments (Gauch and Zobel, 1997) and that the variation in one group must be significantly greater than in the other group, which is observed graphically (Yan and Kang, 2003). In this sense, the graphs do not show the distinct groups for all traits, except for FLOW, in which we verified the formation of three groups; 
this makes it difficult to visualize mega-environments and to reduce costs by eliminating unrepresentative and non-discriminating environments in the evaluation of sorghum genotypes.

The goal of every breeder is an ideal genotype, i.e., one with high adaptability and stability. The GGEBiplot graphs in Figure 3 show the adaptability and stability characteristics of the various genotypes (Yan and Tinker, 2006). From these graphs, the genotype CMSXS643 showed on average the latest (87.51 days) and most stable flowering (Table 2). For GMY, the genotypes CMSXS644 and CMSXS647 stood out, while for TSS, the genotypes CMSXS637, CMSXS646, BRS508, and BR505 were identified. In relation to TBH, which is derived from GMY and TSS and reflects the volume of ethanol to be produced, the genotypes with greatest adaptability and stability were BRS511 and CMSXS647.
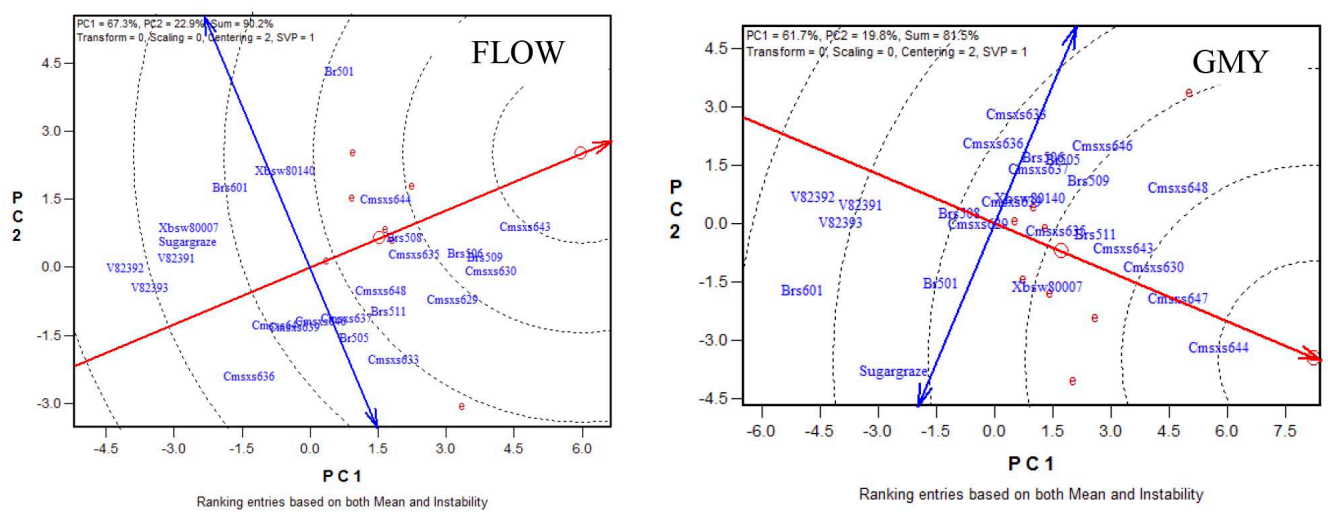

Ranking entries based on both Mean and Instability
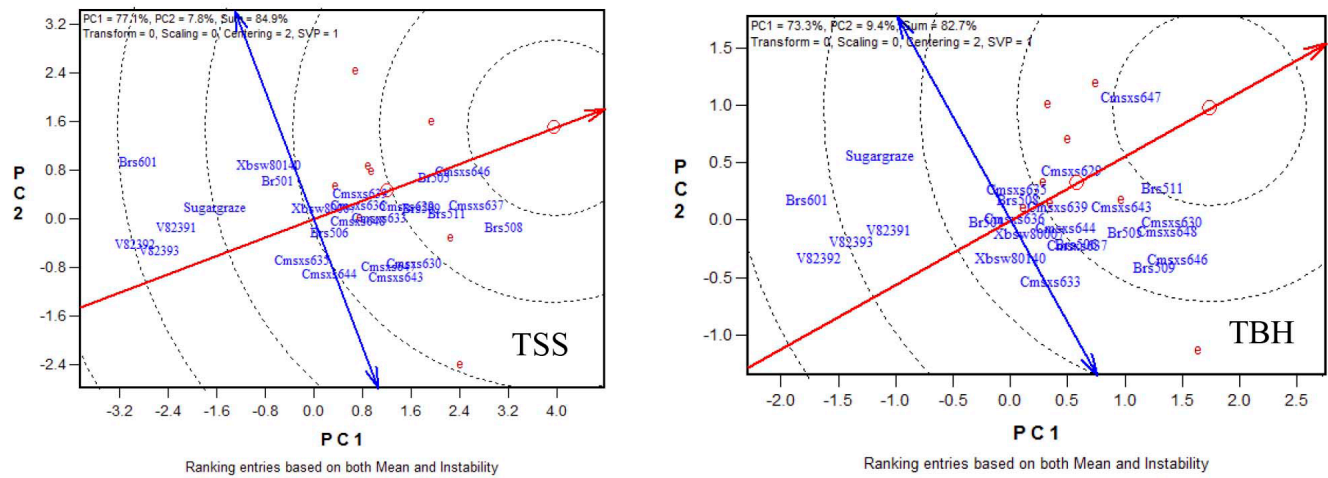

Figure 3. Average-environment coordination (AEC) by the GGEBiplot graph method evidencing the average adaptability and stability of genotypes for the traits flowering (FLOW), green mass yield (GMY), total soluble solids (TSS), and tons of Brix per hectare (TBH).

Although the results of the analysis shown in Figure 3 are of interest, the best option is to have genotypes recommended for different environments from a more reliable recommendation, thus reducing the risk of rejection of the cultivar by farmers. By means of the graphical representation "who-won-where", we observed the behavior of the genotypes in different environments (Figure 2); however, as mentioned previously, the formation of groups 
of environments was not clear. Additionally, Yan and Tinker (2006) suggested that it was essential to check that the pattern of $\mathrm{G} x \mathrm{E}$ interactions was maintained over a number of years.

Table 2. Estimates of means and groups of stability based on stability parameters of sweet sorghum genotypes according to the uni-segmented and bi-segmented models described by Toler (1990).

\begin{tabular}{|c|c|c|c|c|c|c|c|c|c|c|c|c|}
\hline \multirow[b]{2}{*}{ Genotype } & \multicolumn{3}{|c|}{ FLOW } & \multicolumn{3}{|c|}{ GMY } & \multicolumn{3}{|c|}{ TSS } & \multicolumn{3}{|c|}{ TBH } \\
\hline & Mean* & $\mathrm{G}^{\boldsymbol{\Lambda}}$ & $\mathrm{R}^{\#}$ & Mean & $\mathrm{G}$ & $\mathrm{r}$ & Mean & $\mathrm{G}$ & $\mathrm{r}$ & Mean & G & $\mathrm{r}$ \\
\hline BR501 & $83.25^{\mathrm{c}}$ & $\mathrm{E}$ & 0.92 & $36.32^{b}$ & $\mathrm{C}$ & 0.88 & $14.84^{\mathrm{c}}$ & $\mathrm{D}$ & 0.85 & $2.21^{\mathrm{a}}$ & $\mathrm{C}$ & 0.97 \\
\hline BR505 & $79.91^{\mathrm{e}}$ & A & 0.99 & $40.68^{\mathrm{a}}$ & A & 0.98 & $17.78^{\mathrm{a}}$ & $\mathrm{A}$ & 0.98 & $2.95^{\mathrm{a}}$ & B & 0.98 \\
\hline BRS506 & $84.33^{\mathrm{b}}$ & B & 0.99 & $39.01^{\mathrm{a}}$ & $\mathrm{C}$ & 0.96 & $15.30^{\mathrm{b}}$ & $\mathrm{C}$ & 0.95 & $2.64^{\mathrm{a}}$ & A & 0.97 \\
\hline BRS507 & $85.17^{\mathrm{b}}$ & B & 0.99 & $41.11^{\mathrm{a}}$ & A & 0.99 & $17.24^{\mathrm{a}}$ & B & 0.96 & $2.88^{\mathrm{a}}$ & B & 0.98 \\
\hline BRS508 & $83.70^{c}$ & $\mathrm{D}$ & 0.99 & $37.83^{\mathrm{b}}$ & $\mathrm{E}$ & 0.98 & $18.81^{\mathrm{a}}$ & B & 0.92 & $2.51^{\mathrm{a}}$ & $\mathrm{C}$ & 0.95 \\
\hline BRS511 & $81.42^{\mathrm{d}}$ & B & 0.98 & $42.79^{\mathrm{a}}$ & $\mathrm{C}$ & 0.98 & $17.66^{\mathrm{a}}$ & B & 0.97 & $3.17^{\mathrm{a}}$ & A & 0.97 \\
\hline CMSXS629 & $83.27^{\mathrm{c}}$ & A & 0.99 & $38.15^{\mathrm{b}}$ & $\mathrm{D}$ & 0.97 & $16.99^{\mathrm{a}}$ & $\mathrm{C}$ & 0.97 & $2.75^{\mathrm{a}}$ & $\mathrm{E}$ & 0.98 \\
\hline CMSXS630 & $85.75^{\mathrm{b}}$ & $\mathrm{C}$ & 0.98 & $44.74^{\mathrm{a}}$ & A & 0.98 & $16.83^{b}$ & $\mathrm{C}$ & 0.92 & $3.03^{\mathrm{a}}$ & $\mathrm{B}$ & 0.97 \\
\hline CMSXS633 & $80.91^{\mathrm{d}}$ & $\mathrm{C}$ & 0.96 & $35.65^{\mathrm{b}}$ & A & 0.93 & $16.08^{\mathrm{b}}$ & $\mathrm{C}$ & 0.93 & $2.28^{\mathrm{a}}$ & B & 0.95 \\
\hline CMSXS635 & $82.48^{c}$ & B & 0.99 & $41.22^{\mathrm{a}}$ & $\mathrm{C}$ & 0.99 & $14.44^{\mathrm{c}}$ & $\mathrm{C}$ & 0.93 & $2.43^{\mathrm{a}}$ & $\mathrm{C}$ & 0.96 \\
\hline CMSXS636 & $75.43^{\mathrm{f}}$ & $\mathrm{D}$ & 0.97 & $36.26^{\mathrm{b}}$ & A & 0.97 & $15.90^{\mathrm{b}}$ & $\mathrm{C}$ & 0.97 & $2.37^{\mathrm{a}}$ & $\mathrm{C}$ & 0.95 \\
\hline CMSXS637 & $79.59^{\mathrm{e}}$ & $\mathrm{A}$ & 0.99 & $38.08^{\mathrm{b}}$ & A & 0.99 & $17.89^{\mathrm{a}}$ & B & 0.96 & $2.56^{\mathrm{a}}$ & $\mathrm{C}$ & 0.98 \\
\hline CMSXS639 & $78.15^{\mathrm{e}}$ & $\mathrm{D}$ & 0.98 & $39.45^{\mathrm{a}}$ & $\mathrm{C}$ & 0.95 & $16.20^{\mathrm{b}}$ & $\mathrm{C}$ & 0.95 & $2.67^{\mathrm{a}}$ & $\mathrm{C}$ & 0.87 \\
\hline CMSXS643 & $87.51^{\mathrm{a}}$ & $\mathrm{B}$ & 0.99 & $43.80^{\mathrm{a}}$ & $\mathrm{B}$ & 0.97 & $16.28^{\mathrm{b}}$ & $\mathrm{C}$ & 0.90 & $2.90^{\mathrm{a}}$ & B & 0.96 \\
\hline CMSXS644 & $82.35^{\mathrm{c}}$ & E & 0.99 & $49.60^{\mathrm{a}}$ & $\mathrm{B}$ & 0.97 & $14.25^{\mathrm{c}}$ & B & 0.95 & $2.51^{\mathrm{a}}$ & $\mathrm{C}$ & 0.94 \\
\hline CMSXS646 & $78.59^{\mathrm{e}}$ & $\mathrm{C}$ & 0.99 & $42.13^{\mathrm{a}}$ & $\mathrm{E}$ & 0.95 & $18.19^{\mathrm{a}}$ & B & 0.99 & $3.14^{\mathrm{a}}$ & B & 0.96 \\
\hline CMSXS647 & $77.29^{\mathrm{e}}$ & $\mathrm{D}$ & 0.98 & $47.55^{\mathrm{a}}$ & $\mathrm{B}$ & 0.97 & $16.10^{\mathrm{b}}$ & $\mathrm{C}$ & 0.90 & $3.22^{\mathrm{a}}$ & $\mathrm{E}$ & 0.91 \\
\hline CMSXS648 & $81.12^{\mathrm{d}}$ & $\mathrm{A}$ & 0.99 & $45.17^{\mathrm{a}}$ & B & 0.95 & $15.97^{\mathrm{b}}$ & $\mathrm{C}$ & 0.93 & $3.05^{\mathrm{a}}$ & $\mathrm{A}$ & 0.95 \\
\hline BRS601 & $78.33^{\mathrm{e}}$ & $\mathrm{D}$ & 0.94 & $30.78^{b}$ & $\mathrm{E}$ & 0.84 & $12.02^{\mathrm{d}}$ & $\mathrm{A}$ & 0.84 & $1.38^{\mathrm{b}}$ & $\mathrm{D}$ & 0.33 \\
\hline Sugargraze & $75.45^{\mathrm{f}}$ & $\mathrm{E}$ & 0.97 & $36.57^{\mathrm{b}}$ & $\mathrm{E}$ & 0.84 & $12.85^{\mathrm{d}}$ & $\mathrm{D}$ & 0.89 & $1.82^{\mathrm{b}}$ & $\mathrm{E}$ & 0.88 \\
\hline V82391 & $75.36^{\mathrm{f}}$ & $\mathrm{D}$ & 0.97 & $32.01^{\mathrm{b}}$ & $\mathrm{E}$ & 0.98 & $12.26^{\mathrm{d}}$ & $\mathrm{D}$ & 0.84 & $1.73^{\mathrm{b}}$ & $\mathrm{D}$ & 0.86 \\
\hline V82392 & $72.52^{\mathrm{g}}$ & $\mathrm{D}$ & 0.97 & $28.47^{\mathrm{b}}$ & $\mathrm{D}$ & 0.89 & $11.21^{\mathrm{d}}$ & $\mathrm{D}$ & 0.82 & $1.23^{\mathrm{b}}$ & $\mathrm{D}$ & 0.79 \\
\hline V82393 & $73.83^{\mathrm{g}}$ & $\mathrm{D}$ & 0.98 & $30.77^{b}$ & $\mathrm{E}$ & 0.97 & $11.57^{\mathrm{d}}$ & $\mathrm{D}$ & 0.87 & $1.43^{\mathrm{b}}$ & D & 0.92 \\
\hline XBSW80007 & $75.15^{\mathrm{f}}$ & $\mathrm{E}$ & 0.96 & $41.15^{\mathrm{a}}$ & $\mathrm{C}$ & 0.94 & $15.30^{\mathrm{b}}$ & $\mathrm{C}$ & 0.96 & $2.43^{\mathrm{a}}$ & $\mathrm{C}$ & 0.91 \\
\hline XBSW80140 & $79.35^{\mathrm{e}}$ & $\mathrm{E}$ & 0.95 & $39.60^{\mathrm{a}}$ & $\mathrm{C}$ & 0.97 & $14.13^{\mathrm{c}}$ & $\mathrm{C}$ & 0.90 & $2.26^{\mathrm{a}}$ & $\mathrm{C}$ & 0.93 \\
\hline
\end{tabular}

* Means followed by the same superscript letters belong to the same group by the Scott-Knott test at $5 \%$.

${ }^{\Delta}$ Classification of groups of stability by the Toler method. \#Association between the mean observed and estimated according to the fit to the bi-segmented or uni-segmented model of the Toler method.

Toler (1990) stated that a genotype must present a satisfactory performance in various environments in order to provide resilience in poor environments, i.e., maintaining acceptable yields and demonstrating responsiveness with improvements of environmental conditions. Various genotypes showed a good fit to the bi-segmented Toler model (1990) $\left(H_{0}: \beta_{1 i} \neq\right.$ $\beta_{2 i}$ ), with doubly desirable responses $\left(\beta_{1 i}<1<\beta_{2 i}\right)$ and good predictability of performance $(\mathrm{r}$ $>$ 0.84): for FLOW, CMSXS629, CMSXS637, and CMSXS648; for GMY, BR505, BR507, CMSXS630, CMSXS633, CMSXS636, and CMSXS637; for TSS, BR505 and BRS601; for TBH, BRS506, BRS511, and CMSXS648 (Table 2). In this context, Rosse and Vencovsky (2000) suggested that the major problem faced by breeders is to identify a productive genotype with doubly desirable responses. For instance, for GMY, only the genotypes in group A (BR505, BR507, and CMSXS630) were categorized with statistical significance as best adapted. For TSS, the genotype BR505 exhibited good adaptability, while genotype BR601 was not well adapted (Table 2).

The use of two or more methods to study adaptability and phenotypic stability is only justified if both are complementary. In this regard, the GGEBiplot analysis found that the genotypes BRS511 and CMSXS647 combined good adaptability and stability for the trait TBH. Considering the fit given by the Toler method, it can be further inferred that genotype BRS511 
showed a satisfactory performance in both favorable and unfavorable environments, while genotype CMSXS647 was doubly undesirable, i.e., showed markedly reduced production under poor environmental conditions and was unresponsive to favorable environmental conditions. Souza et al. (2013), using the Annicchiarico method, also classified genotype BRS511 as adapted and stable, emphasizing the recommendation of this genotype as a cultivar.

The additional detail on responses of genotypes to environments provided by the Toler method is enlightening and informative with regard to decision making by a breeder. Probably, this was because the GGEBiplot method uses linear correlations between genotypes or environments based on principal component analysis (Yang et al., 2009). Since TBH is estimated from GMY, \%EXT, and TSS, this trait cannot present as a linear response; thus, the GGEBiplot method cannot explain the pattern of response of BRS511 and CMSXS647, unlike the Toler method.

The simultaneous use of Toler and GGEBiplot methods showed that CMSXS648 was doubly desirable by the Toler method for TBH (Table 2), but it was located in the second concentric circle by the GGEBiplot method (Figure 3). Thus, the GGEBiplot method as traditionally applied did not provide an inference about the scores, but the Toler method could be used in a complementary manner to better characterize the genotype.

The genotypes considered as doubly desirable by the method of Toler were the varieties (lines); most cultivars (commercial hybrids), such as BRS601, Sugargraze, V82391, V82392, and V82393, were unstable by the GGEBiplot method (Figure 3) and were doubly undesirable by the method of Toler (Table 2). Thus, the genetic structure of the genotypes deserves consideration as lines are expected to be less stable due to lower heterozygosity and heterogeneity compared to hybrids (Ramalho et al., 2012).

Only one of seven hybrids showed doubly desirable stability for TSS (BRS601); however, it was in the group with the lowest average, being a stable genotype with low adaptation, which is not desirable. The other hybrids, Sugargraze, XBSW80007, and XBSW80140 for FLOW, BRS601, Sugargraze, V82391, and V82393 for GMY, and Sugargraze for TBH were classified as doubly undesirable. According to Ramalho et al. (2012), the finding that hybrids are more stable in sorghum (grain and forage) and wheat encourages their use in autogamous plants; however, this effect was not observed in our study.

Overall, the simultaneous use of GGEBiplot and Toler methods was justified because it allowed a better characterization of genotypes given the G x E interactions, and enabled the identification of genotypes with better adaptability and phenotypic stability in the different environments evaluated. The genotype BRS511 proved to be the most adapted and stable for TBH using these methods; the GGEBiplot method also found that the CMSXS647 line was adapted and stable for this trait in the environments evaluated.

\section{Conflicts of interest}

The authors declare no conflict of interest.

\section{ACKNOWLEDGMENTS}

The authors are grateful to Embrapa Maize and Sorghum and all collaborators of the trials network of sweet sorghum, and for the financial support of the National Counsel of Technological and Scientific Development - CNPq, Brazilian Federal Agency for Support and Evaluation of Graduate Education - CAPES, and Minas Gerais State Research Foundation - FAPEMIG. 


\section{REFERENCES}

Ferreira DF and Zambalde AL (1997). Simplificação de algumas técnicas especiais da experimentação agropecuária no MAPGEN e softwares correlatos. In: Congresso da Sociedade Brasileira de Informática, Belo Horizonte, 285-291.

Ferreira DF, Demétrio CGB, Manly BFJ, Machado A de A, et al. (2006). Statistical models in agriculture: biometrical methods for evaluating phenotypic stability in plant breeding. Cerne 12: 373-388.

Gauch HG (2013). A simple protocol for AMMI analysis of yield trials. Crop Sci. 53: 1860-1869.

Gauch HG and Zobel R (1997). Identifying mega-environments and targeting genotypes. Crop Sci. 37: 311-326.

Mattos PHC de, Oliveira RA de, Filho JCB, Daros E, et al. (2013). Evaluation of sugarcane genotypes and production environments in Paraná by GGE biplot and AMMI analysis. Crop Breed. Appl. Biotechnol. 13: 83-90.

Oliveira RL de, Von Pinho RG, Balestre M and Ferreira DV (2010). Evaluation of maize hybrids and environmental stratification by the methods AMMI and GGE biplot. Crop Breed. Appl. Biotechnol. 10: 247-253.

Ramalho MAP, Abreu A de FB, Santos JB and Nunes JAR (2012). Aplicações da genética quantitativa no melhoramento de plantas autógamas. Editora UFLA, Lavras.

Rao PS, Reddy PS, Rathore A, Reddy BVS, et al. (2011). Application GGE biplot and AMMI model to evaluate sweet sorghum (Sorghum bicolor) hybrids for genotype x environment interaction and seasonal adaptation. Indian J. Agric. Sci. 81: 438-444.

Resende MDV de and Duarte JB (2007). Precisão e controle de qualidade em experimentos de avaliação de cultivares. Pesqui. Agrop. Trop. 37: 182-194.

Resende MDV de, Resende RMS, Jank L and Valle CB do (2008). Experimentação e análise estatística no melhoramento de forrageiras. In: Melhoramento Forrageiras Tropicais (Resende RMS, Valle CB do and Jank L, eds). Embrapa Gado de Corte, Campo Grande, 195-287.

Rosse LN and Vencovsky R (2000). Modelo de regressão não-linear aplicado ao estudo da estabilidade fenotípica de genótipos de feijão no estado do Paraná. Bragantia 59: 99-107.

Scott AJ and Knott M (1974). A cluster analysis method for grouping means in the analysis of variance. Biometrics 30 : 507-512.

Souza VF de, Parrella RA da C, Tardin FD, Costa MR, et al. (2013). Adaptability and stability of sweet sorghum cultivars. Crop Breed. Appl. Biotechnol. 13: 144-151.

Toler JE (1990). Patterns of genotypic performance over environmental arrays. Doctoral thesis, Clemson University, Clemson.

Toler JE and Burrows PM (1998). Genotypic performance over environmental arrays: A non-linear grouping protocol. $J$. Appl. Stat. 25: 131-143.

Yan W (2001). GGEbiplot - A windows application for graphical analysis of multienvironment trial data and other types of two-way data. Agron. J. 93: 1111-1118.

Yan W (2013). Biplot analysis of incomplete two-way data. Crop Sci. 53: 48-57.

Yan W and Kang MS (2003). GGEBiplot analysis: a graphical tool for breeders, geneticists, and agronomists. CRC Press, Boca Raton.

Yan W and Tinker NA (2006). Biplot analysis of multi-environment trial data: principles and applications. Can. J. Plant. Sci. 86: 623-645.

Yan W, Pageau D, Frégeau-Reid J and Durand J (2011). Assessing the representativeness and repeatability of test locations for genotype evaluation. Crop Sci. 51: 1603-1610.

Yang R-C, Crossa J, Cornelius PL and Burgueño J (2009). Biplot analysis of genotype x environment interaction: proceed with caution. Crop Sci. 49: 1564-1576. 